\title{
INDIA: THE FUTURE OF HEALTHCARE POST COVID-19, LEARNING FROM DIVERSITY
}

\author{
DS Briggs AM
}

Editor in Chief,

This special issue has its focus on the nation state of India, its healthcare system and health services. You may well ask why a special issue on India and the simple response would be that our colleagues from the K. J. Somaiya Institute of Management (K J SIM), Mumbai, India approached the Journal to see if we would publish a special issue base on articles that were presented at the 1st Annual Conference on Healthcare Management conducted earlier this year by them. [1]

We agreed to this request because India is part of our geographic area of interest of the Asia Pacific, and we already receive significant contributions from authors from India. Secondly, India and Australia have connections that go back to colonial times and as members of the Commonwealth countries. In addition, Australia is a multicultural country and people from India now represent more than 7 per cent of that population. Up until the Covid Pandemic India was also a source of international students to Australia. Importantly, in the Australian health system we increasingly depend on a workforce that has come from overseas, particularly in regional, rural, and remote parts of Australia.

In the current geo-political context, there is increasing recognition of the need for closer working relationships between these two countries couched in the term 'IndoPacific' relationships. The organisations that produce this Journal, the Australasian College of Health Services Management (ACHSM), the professional College for health managers and the Society for Health Administration Programs in Education, the representative group of health management programs in Australia universities welcome affiliation with likeminded organisations in other countries. Both organisations work together and have increasing affiliated members and organisations in New Zealand,
Hong Kong, Thailand. Importantly, both organisations see the merit in increasing international relationships.

This Editor has always had the conviction that you can best learn health management from studying diversity amongst health systems, not just by studying what is taught as theory and not just from services and systems that are in front of you, that is from your own hospital or health system. As teachers, academics, and health professionals we should encourage diversity in learning contexts and experiences because that forces us to compare and that assists us in being more analytical and critical and to practice continuous learning as all true professionals should.

Not all health management learning is formal and much of what we learn is also experiential and, in my view, learning is enhanced when it occurs with and from others. This does not necessarily occur in formal contexts. Importantly, these days with the technology available we can do this remotely but in learning networks, often called communities of practice (COPs) or even in distributed networks of practice (DNOPs). With technology, we can now network effectively despite being geographically distant.

So why should our learning be global just not local? The Covid Pandemic in part provides the answer. That occurrence demonstrates ongoing global threats from communicable diseases, bioterrorism, violent crime, wars, human trafficking are examples of a few reasons why health systems and health knowledge needs to be viewed from global perspectives. Our rapid acquisition of new technologies and pharmaceuticals are themselves globalised and both require access to international markets by health systems to procure and utilize. Most importantly, nation states should be communicating their 
experiences of the causes, effects, and outcomes of the pandemic so that lessons can be learned and that collaboratively we can improve our understanding of these types of challenges into the future. This 'post covid' issue of the Journal based on the Indian experience should be used by all readers as an important learning experience for the future.

At the time of writing this editorial I am also preparing a presentation for a Hong Kong based international conference, Hong Kong Polytech University, CPCE Health Conference 2021 on the post covid pandemic and implications for long term care. So, another learning opportunity where colleagues from the Asia Pacific will present perceptions and findings from their individual nation states experience of the Covid pandemic. It is encouraging that the Journal is an active participant in these important events.

It is important in our learning from these events is that most organisations and, health systems are slow to accept and implement change and health reform. A colleague of mine once said that we tend to procrastinate and resist change in health systems. [2] Others have gone further stating that 'a paradoxical pattern of policy development' is describe as 'reform without change and change without reform'. This author suggests that in highly centralised governance, health reform is difficult. [3]

The important message from this editorial is for readers to be strategic in reflecting on the lessons learned from the pandemic and to resist being reactive. It would help if you framed your reasoning by asking questions such as "what problem are we attempting to resolve and whose interests are being served?'

\section{DS Briggs AM}

Editor in Chief

\section{References}

1. K. J. Somaiya Institute of Management (K J SIM), Mumbai, India accessible at https://simsr.somaiya.edu/en.

2. Leeder, S. (2017). The Desirability of Zero Tolerance for Procrastination. Asia Pacific Journal of Health Management, 12(3), 8-10.

https://doi.org/10.24083/apjhm.v12i3.49
3. Hacker JS. Review Article: Dismantling the Health Care State? Political Institutions, Public Policies and the Comparative Politics of Health Reform. British Journal of Political Science. 2004; 34:693-724, doi:10.1017/S0007123404000250

\section{EDITOR'S NOTE:}

This issue and the editorial were compiled at a time when the national political leaders of India and Australia were meeting in the USA to develop further collaborations between out two countries. Health and education are obvious choices for collaboration. So I have included the contact details of the two APJHM parent organisations to allow our authors, reviewers and readers to take the opportunity to be in touch with each other.

Australasian College of Health Services Management ACHSM for professional development, certification, networking for health service managers at

https://www.achsm.org.au/

The Society for Health Administration Programs in Education SHAPE for education in health management, research, academic programs, doctoral students at

shape.symposium@gmail.com 